\title{
The science-technology-society framework for achieving scientific literacy: an overview of the existing literature
}

\author{
Steven M. Autieri ${ }^{*}$, Aidin Amirshokoohi², and Mahsa Kazempour ${ }^{3}$ \\ ${ }^{1}$ Science Department, Academy for Technology and Academics Conway, SC USA \\ 2 Department of Education, DeSales University Center Valley, PA USA \\ ${ }^{3}$ Department of Childhood Education, Penn State University Berks Campus, Reading, PA USA \\ For correspondence: smautieri@gmail.com
}

\begin{abstract}
This literature review intends to highlight some of the critical research that has been synthesized on the perspectives of both teachers and students and their attitudes to teaching and learning in an STS-themed learning environment. The first portion draws on the perspectives of elementary and secondary school teachers both locally and abroad. The information collected is intended to illustrate some of the major successes, as well as barriers to implementation in several different classrooms. The review will present data focusing on the overall attitude and educational successes of students that participate in an STS-enriched learning environment. By examining the current research on STS, it is expected that a clear picture will be created demonstrating the place of STS in the overall science curriculum. The conclusion of the review will also aim to indicate disparities still present in the growing body of STS research and areas of future focus.
\end{abstract}

Keywords: Science, Technology, Society, Inquiry-based learning

\section{Introduction}

Science education reform efforts, over the last several decades, have been rather unsuccessful in creating major change in the way science is taught in the classrooms. The Report of the 2012 National Survey of Science and Mathematics Education concluded that over three-fourths of teachers surveyed across the various grades felt that it was more beneficial for topics to be covered in greater depth than breadth. Alarmingly; however, the majority of respondents surveyed still deemed it necessary to introduce key vocabulary and concepts to students at the beginning of a lesson (Banilower, 2013).

The science education community has continually attempted to explore and promote the implementation of new and creative approaches to make the teaching and learning of science a successful endeavor for teachers and students alike, and, in doing so, achieve the overarching goal of developing a scientific literate society (Bybee, 2000). An example of one such significant reform initiative, with the aim of achieving scientific literacy, is the Science-Technology-Society (STS) movement, which began several decades ago, and promotes the teaching of science in a socially contextualized approach. In an STS-based classroom, students investigate issues in a manner that promotes real-world connections between the classroom and society (Rubba, 1991).

STS education aims to align with the goals of science education, as outlined in documents such as the NSES (NRC, 1996) and the most recent Framework for K-12 Science Education (NRC, 2011) and the Next Generation Science Standards (NRC, 2013). These documents advocate for a cross-disciplinary approach to teaching scientific content from a socially contextualized perspective (NSES, 1996; NGSS, 2011). Furthermore, they highlight the significance of providing students with opportunities to engage in real-life, contextualized, and exploratory science experiences to develop skills such as argumentation, critical thinking, reasoning and decision-making. STS education promotes and encourages students 
to critically examine scientific issues from an analytical perspective and learn how to acquire, comprehend, and evaluate scientific knowledge. Students must also be granted the opportunity to select topics that are of central importance to them personally. STS allows students to select an issue, create a vantage point and defend that perspective through scientific research and questioning. When students have the ability to design and conduct scientific investigations, and create connections between scientific concepts and societal issues, they will have thoroughly developed a concrete understanding of the nature of scientific inquiry. Students need to be able to apply scientific knowledge to solve real world issues (Slack \& Stewart, 1990) which are deeply rooted in historical, political, cultural, sociological, an ethical contexts. (Pedretti, 1999). Perhaps, Robert Yager best described the importance of STS when he stated that, "STS is science that goes beyond the limits of the textbooks and into the real world" (Kumar \& Fritzer, p.14, 1998). Confronting these issues in the science classroom will provide a strong foundation to the decision-making skills our students need to become scientifically literate, contributing citizens in society (Abd-El-Khalick, 2003).

Current educational endeavors in the American school system seem to address urging societal issues in the wrong context. Often times, students are introduced to pressing issues, such as global warming or habitat destruction, with little connection to how these concerns play a role in the everyday lives of the students. Secondly, there is little opportunity, even on a superficial level, for students to learn about or utilize the technological advances available in the field. The main goal of technology is to develop the skills and knowledge necessary to handle many of the pressing issues society deals with. Thus, technology and social issues appear to have a significantly interrelated relationship (Aikenhead, 1992). The social, democratic, and economic success of our society is tremendously dependent on not only the scientific, but also the technological literacy of the citizenry (Bybee, 2000; Yalvac, 2007). In summary, STS education aims to meet the goal of scientific literacy by promoting the teaching and learning of science through the context of the individual in society so that students gain essential science skills and the ability to think critically, make informed decisions, solve problems, work collaboratively, and be technologically efficient (Yager, 2007; Mansour, 2009).

\section{Historical Perspectives}

The fundamental purpose of Science, Technology, and Society (STS) was stated in the early 1990's by Aikenhead when he indicated that, "Our best hope for the resolution of STS issues are citizens literate in science and technology, and empowered to make informed decisions and take responsible action" (Aikenhead, p.1, 1992). STS programs were common practice in European countries before finding their way to the United States. Major programs can be located throughout the UK, such as Science and Society and Science in a Social Context as well as in Canada titled SciencePlus (Harms \&Yager, 1981; Yager, 2006). Since then, the use of STS as an instructional approach in the United States has increased dramatically. In 1984, a study conducted found that in 22 textbooks published between the years 1963 and 1983 little to no emphasis was placed on relevant socio-scientific issues (Bybee, 1991). It can now be located in most science classroom textbooks, and is recognized as a critical component of science education programs by the National Science Education Standards, the Benchmarks for Scientific Literacy, and the National Science Teachers Association (Meyer \& James, 2002). In 1980, the National Science Teachers Association published a position statement on STS:

“The goal of science during the 1980's is to develop scientifically literate individuals who understand how science, technology, and society influence one another and who are able to use their knowledge in their everyday decision-making. The scientifically literate person has a substantial knowledge base of facts, concepts, and conceptual networks, and process skills that enable the individual to learn logically. This individual both appreciate the value of science and technology in society and understand its limitations" (NSTA, p. 1, 1982).

The first use of the term STS was during the 1960's in an attempt by educators to address issues facing society (Meyer \& James, 2002). John Ziman did not officially describe STS until the early 1980's in his book Teaching and Learning About Science and Society. Ziman argued that science needs to be addressed in a curricular approach that makes the content material more relevant to the everyday lives of the students (Yager \& Lim, 2006). One of the first major grants provided to conduct STS 
research was awarded in 1995 by the National Science Foundation to investigate the effects that the STS approach would have on students from kindergarten through college. Subsequent grants have been furnished in an attempt to make STS programs universal throughout all fifty states (Yager, 1993).

\section{Rationale}

The current literature review aims to synthesize existing research on (a) students' views of STS, (b) the impact of STS-based K-16 science education on students' attitude, beliefs, and learning, (c) teachers' views toward STS issues and STS-based instruction, and (d) the impact of teacher professional development, both at the pre-service and in-service levels, on teachers' views and attitude toward STS-based instruction. It is critical to examine the advances that have been made, in the past several decades, toward the implementation of STS programs in schools and teacher preparation institutions throughout both the United States and abroad and the impact of such measures. Furthermore, in an effort to expand STS-based projects in schools and teacher preparation, this review aims to examine the existing literature in order to shed light on factors that may play a role in either facilitating or impeding the implementation of STS-based programs. Finally, the review will discuss gaps within the literature and areas that remain to be explored in order to provide a framework for future research.

\section{Literature Review}

The literature review was conducted utilizing a best-evidence approach, which looks to the logical inclusion of information based on the development of inclusion criteria (pre-service vs. in-service teachers views, views of students, etc.). Sources were selected through either broad Internet searches or from citations in electronic databases. The electronic databases surveyed included ERIC, Education Research Complete (EBSCO), Educators Reference Complete (Gale), and JSTOR. Initial search criteria utilized either the keywords "STS" or "Science-Technology-Society." To narrow the range of sources after the initial search, sources were screened for their connectivity to history of STS implementation, implications to classroom practice, and teacher education preparation. Sources were also screened for significant contributions dated post-1990. The review included 31 articles from 18 peer-reviewed journal sources, 2 reviews, 1 conference paper, 2 policy papers, and 1 book chapter.

Figure 1 summarizes the research, focusing on K-12 students and teachers' perspectives on STS education and the impact of such programs on their learning and attitude, which will be discussed in this review of the literature. The first section examines the overall attitude and educational successes of students that participate in a constructivist style, STS learning environment. The second section focuses on the perspectives of both pre-service and in-service elementary and secondary school teachers. The information collected is intended to illustrate some of the major successes, as well as barriers to implementation in several different classrooms. By examining the current research on STS, it is expected that a clear picture will be created demonstrating the place of STS in the overall science curriculum. The conclusion of the literature review will highlight existing gaps in the STS literature and suggest future directions for research. 


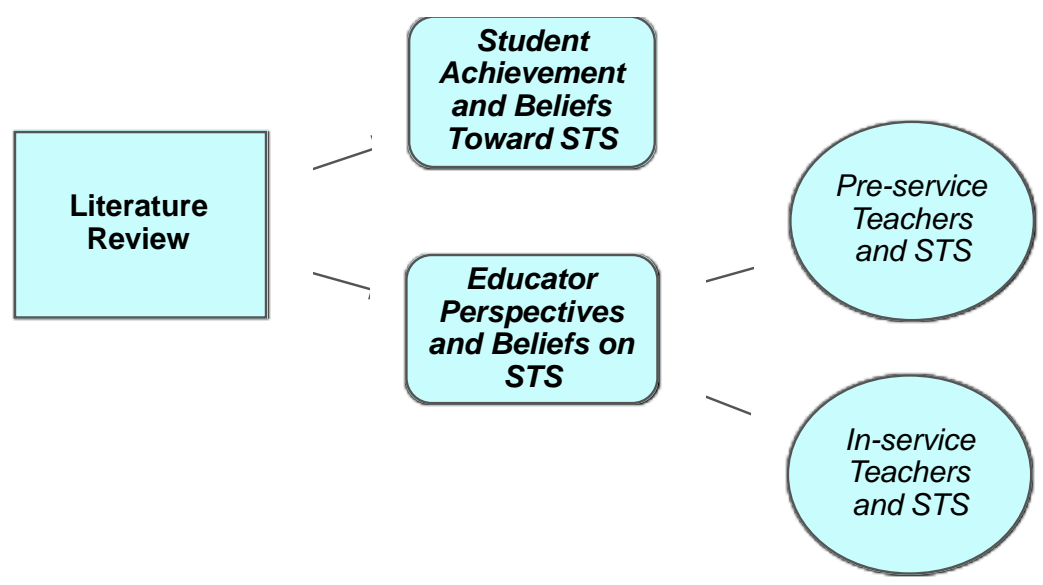

Figure 1: Overview of Emergent Themes for the Literature Review.

\section{Student Perspectives on Science, Technology, and Society}

It is critical to examine the viewpoints and academic gains of students participating in an STS-themed learning environment. This section discusses several studies that examine the social, academic, and citizenship gains of students. Figure 2 summarizes empirical studies reviewed on student attitudes toward STS. Several studies mentioned in a prior review article by Yager (1993) illustrate the effective nature of STS toward student learning and motivation. It was demonstrated that students who were exposed to STS were four times more likely to be able to apply their scientific knowledge in new contexts, while interest in learning science increased by a factor of two. Students were more likely to exhibit creativity skills, process skills, and greater concept mastery.

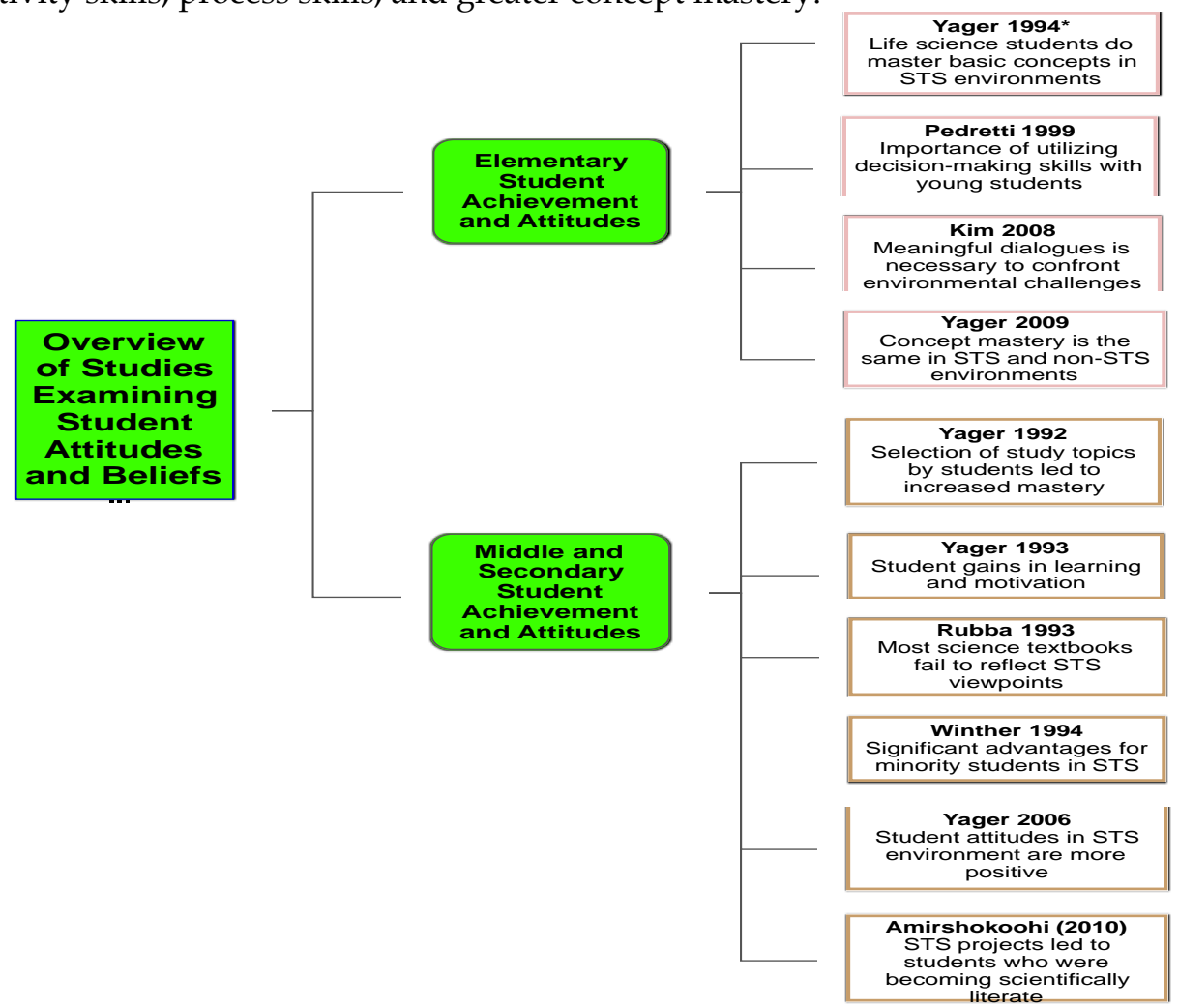

Figure 2: Graphic organizer of research pertaining to student beliefs and attitudes toward STS.

A study conducted by Yager (1992) was conceived as a way to examine differences in learning between undergraduate majors studying biology in a format that allows for the examination of issues compared to students who solely focus on the subject matter in a concept-oriented format. Assessment of student learning was assessed utilizing five domains. Knowledge and assessment of 
concepts were assessed utilizing the Assessment Battery for the Concept Domain (ABCD). Understanding of the science processes was assessed utilizing the Welch Science Process Inventory (SPI). Creativity was assessed utilizing the creativity test as part of the Iowa Assessment Package. Finally, attitude was assessed by the Attitudes, Preferences, and Understanding Test. The study presented some dramatically promising results. Although students were at first hesitant in participating in the STS domain, the realization of selecting topics and focal points to study in relation to the topic seemed to correlate with a mastery of basic concepts possibly due to greater student motivation. Students also seemed to become increasingly interested in the discipline of biology and pursuit of careers in the field.

Rubba and Harkness (1993) examined both the textbooks used in science classrooms, as well as instructional strategies of many teachers. The findings suggested that science textbooks fail to reflect an STS viewpoint toward many science topics and instructional strategies being utilized in the classroom fail to mention STS at all. Therefore, students find little interaction with STS themes in their science classes. Textbooks that are geared toward STS must present information in a manner that allows the student to construct their own meaning towards a concept (Aikenhead, 1992). Data was collected in this study with the use of two instruments, the Teachers' Beliefs about Sciencetechnology-Society (TBA-STS) instrument and the VOST instrument. The study found that while many students began to reexamine their beliefs and conceptions on science, some students moved toward misunderstandings in particular areas.

One of the most notable and relevant studies conducted, especially to our current national concern, deals with a study conducted by Winther (1994) examining achievement of minority students in an inner-city high school learning in a traditional versus an STS-based chemistry course. The study aimed to examine whether Chemcom, an STS-based curriculum, could effectively raise the achievement of African-American students in a large midwestern high school. Chemcom focuses on a mainly cooperative curriculum where learners can relate new concepts to preexisting ideas. It was seen that a statistically significant difference could be observed between the two groups indicating that learning in an STS-themed environment was beneficial even for minority students. Few studies exist examining the achievement scores of students from other minority populations.

Yager (1994), as part of the Iowa Chautauqua Program, conducted a brief study examining the success of STS in the Life Science classrooms for students in grades 4-12. One of the largest concerns by both pre-service and in-service teachers as mentioned previously was the concern that "it's not real science." Yager demonstrated that students DO learn basic concept while developing creativity and process skills in an STS environment. The study utilized both novice and expert teachers and demonstrated that the gains were as a result of the impact of STS training regardless of the level of teaching experience.

Overall, enhancing a curriculum with STS themes provides several benefits to students. Yager (1995) found that providing opportunities for exploration in the classroom, many teachers see the benefit in using the problem or issue as a means for exploration. When students are attempting to solve a problem, the research they conduct provides the means for searching for relevant content information. By synthesizing the results of their research in an authentic manner, students effectively demonstrate their total comprehension of the subject material. Importantly, Yager points out that utilizing STS will help to elicit misconceptions to be addressed. While it seems as a long, and rather unknown road ahead, with the proper training and professional development, teachers can understand the ease and benefits of such pedagogy.

It should be noted that some studies have looked for the presence of STS pedagogy in the classroom but have found its use lacking. Totten and Pedersen (1996) noted in their study focusing on secondary students finding that "teacher-talk" was the primary means for examining issues in the classroom of social and scientific importance. Over twelve percent of high school students that 
responded overwhelmingly indicated that science was not the discipline that they were able to ponder social issues in society.

Pedretti (1999) conducted a study that examined how fifth- and sixth-grade students interpreted an issue with multiple perspectives, while determining how the school community and out-of-school contexts can support informed conversation and decision-making around these issues. The qualitative case study utilized an issue-based approach and examined the perspectives of a combined group of fifth- and sixth-grade students in both a classroom and informal learning setting called Science World. This study demonstrates the importance of utilizing decision-making and critical thinking skills with young children. The findings indicate that using a town meeting strategy can encourage students to think critically about a controversial socioscientific issue of concern. When students had to do the research and understand the problem, they were not only gaining invaluable science skills, but were enthusiastic and motivated about learning. Teachers must provide students with the opportunities to use these critical thinking skills to reach and defend informed decisions.

A recent qualitative action research project by Yager and Yager (2006) consisted of two case studies compared in a side-by-side analysis. The study involved two sections of middle school science classes taught by different teachers. One teacher followed the textbook dominated approach, while the other teacher utilized an STS-based approach to teaching. The first research question dealing with mastery of science concepts between the two approaches was investigated by distributing short, weekly quizzes focusing on major textbook concepts. The second research question aimed at how well students were able to apply new information into new contexts was measured by teacher led inquiries about the use of ideas and concepts beyond the classroom. Researchers utilized the Expert Science Teacher Evaluation Model (ESTEEM) instrument to collect data on student creativity. The attitude of textbook students was concluded to be more negative than the opinions and attitudes of those in an STS environment. It was also observed that there was no significant difference in the mastery of concepts between the two learning environments. However, students in the STS dominated environment provided significantly more suggestions for further uses of the information outside the current lesson. The STS students asked more valuable questions, provided more valid explanations, and suggested methods for testing the explanations more than the textbook dominated students did. Based upon analysis of the ESTEEM instrument, it was observed that STS classrooms provided more indication of constructivist practices being implemented.

Studies have been conducted examining the connections of STS-based instruction and student creativity and motivation. Lee (2007) administered two surveys, the Attitudes Toward Science Inventory (ASI) and the Assessment of Student Creativity (ASC), to middle and high school students before and after and STS-based course. Positive attitudes increased with students taught by STS approaches, while attitudes decreased with students taught in a traditional fashion. The findings also indicated improvements in creativity among students taught with an STS approach, except with the questioning subscale. The results of the study demonstrate that it is possible for students to appreciate the STS method and adapt it to improve in performance even if exposed to STS-based instruction for a brief period of time.

Kim (2008) focused on the perspectives and viewpoints of elementary students studying ecosystem STS issues in a Korean classroom. The intended purpose of this study was to acquire the significance of Science, Technology, Society, and Environment (STSE) knowledge in the form of children's knowledge of the environment. Kim utilized the Children's Environmental Attitudes and Knowledge Scale (CHEAKS) instrument to gain a better understanding of the knowledge and perspectives of the children about the environment, and the Relevance of Science Education (ROSE) questionnaire to measure the understanding of relationships between science, technology, and the environment. The study found that even though $85 \%$ of students understood that they play a significant role in making appropriate decisions for the environment, they felt they were unable to take effective action in solving these problems due to their age.

Yager (2009) conducted a research study in which fifteen teachers in grades four through six from five different school districts each taught two sections of science-one utilizing a Science, Technology, 
Society (STS) approach, and a second in a traditional textbook-centered manner. It was determined that on average, the STS sections differed significantly from the non-STS sections across six domains including concept, process, application, creativity, attitude, and worldview. The STS sections differed from the non-STS group in all domains except for concept acquisition across the three different grade levels. Thus, concept mastery was not devalued whether a traditional or STS approach was being utilized for this study. The other six domains measured were significantly different between the two environments indicating that learning in an STS environment is more effective than a non-traditional one.

As mentioned previously, Yager (1993) demonstrated that students who are exposed to environments emphasizing an STS instructional pedagogy are more likely to gain interest in science and science careers. Yoruk (2009) examined the effects on student achievement and career choice after STS implementation. Two groups of students received a lesson on separating mixtures. However, students in the treatment group received the lesson utilizing an STS 5E instructional format, while students in the control group received the lesson utilizing a traditional learning format where activities were teacher and textbook centered. Approximately two weeks before the start of the study, the Chemistry Achievement Test (CAT) and the Academic Identity Test were administered to the subjects to determine student interests and career intentions. Both of these tests were also administered again approximately two weeks after the conclusion of the study. The study found that the student achievement levels of the students involved in the STS environment increased at the conclusion of the study but no increase was evident in the control group. The STS students also found themselves to be more likely to participate in social responsibility studies as well. After the STS study was concluded, these students were also more likely to have tendencies to select science and technology related career fields. The findings suggest that teaching should emphasize and be linked to real life topics. Thus, teachers should be teaching skills and knowledge in conjunction with links and issues in everyday life.

One study provided an accurate portrayal of the interactions students have with their environments in an STS study called the Biodiversity Community Action Project. Amirshokoohi and Kazempour (2010), working with freshmen and sophomore biology students in a rural Midwestern community, decided to incorporate a class project which allowed students to examine the relationships between organisms and ecological and environmental issues. Students became involved in a three-stage process where students conducted research on the characteristics of a particular taxonomic group and an STS issue related to that group. The students eventually decided that the project could serve as a means to become involved in the community and also to help educate the public. Projects ranged from articles to local newspapers to initiating community river clean up. In the final phase of the project, students prepared presentations that were used to teach their peers about their study focus. Students gained a better understanding of the interaction among organisms and the impact of environmental issues on organisms. They also recognized the role humans can play, either positively or negatively, on impacting the environment.

\section{Summary}

NSTA has suggested the importance of teaching and learning science from the human perspective (NSTA, 2010). The STS curriculum aims to create citizens capable of making informed decisions about complex societal issues (Pedretti, 1999; Amirshokoohi, 2010; Yager, 2009). Students perceive the way that the science content encountered in the classroom impact their daily lives. The studies reviewed here suggest that all students, including minority students (Winther, 1994), participating in classroom instructional environments promoting STS pedagogy are more likely to develop higher levels of creativity, processing skills, and application of content than non-STS students (Yager, 1994; Yager, 2009). These students leave public schools with the ability to exercise decision-making skills necessary to implement solutions in the local and global community (Pedretti, 1999; Rubba, 1991). 


\section{Teacher Perspectives on Science, Technology, and Society}

Given the emphasis of science education reform on the inclusion of STS, major efforts have been made over the last twenty years to understand how teachers and students alike view STS and promote increased implementation of STS instruction in the classrooms. STS relies on a combination of several proven educational techniques. These include, but are not limited to, cooperative learning strategies, student-derived actions, brainstorming, panel discussions and debates, and field experiences. Mansour (2009) has cited lack of adequate preparation as one of the key reasons for teachers to not adopt an STS framework to teaching science. Teachers must be involved in the critical process of developing curriculum which will in turn help to shape the beliefs and perspectives teachers have toward STS instruction. This section will attempt to highlight several of the studies that have focused on examining the perspectives and opinions of pre-service and in-service teachers toward STS-based strategies.

\section{In-Service Teacher Views of STS Education: A Gap In the Road?}

\section{Limitations between policy and practice}

The enduring question that seems to permeate the discussion on STS practices is why despite its benefits the STS framework of teaching is not being adopted extensively in the classrooms? In the past few years, a number of researchers have attempted to isolate the reason(s) that STS never makes it from the policy briefs to the classroom. This section focuses on a select group of studies that have targeted this very question and have attempted to provide implications to educators based on their findings. Several of these perceived barriers to implementation are presented in a succinct summary with the relevant studies in Figure 3 at the conclusion of this section.

Rubba (1991) speculated why many teachers fail to implement STS curriculum in their classrooms. The study revealed that many teachers do not feel prepared to teach or implement STS. The study concludes that while science education reforms have touted STS education, many science teachers avoid STS, labeling it simply as just another reform policy and citing insufficient preparation as a major obstacle. One of the major gaps of the literature pertains to the limited amount of information on the extent of in-service and pre-service science teachers' STS training. Oftentimes, teachers' beliefs about their role as the expert and dispenser of knowledge as opposed to the facilitator of student learning, which is central to the STS framework, serve as an additional obstacle. Science teachers need to examine their own values and beliefs as pre-service candidates before STS practices can be successfully implemented.

Bybee (1991) suggested that a gap exists between policy and practice with regards to STS. Detailed analysis of sixth and seventh grade science textbooks and tenth-grade biology textbooks revealed little to no mention of STS relevant issues. While STS instructional resources are available to teachers, the taught curriculum fails to reflect these approaches. Support seems to be the missing piece needed to provide direction to teachers to increase relevance of practice.

Lumpe (1998) found that teachers failed to implement STS approaches in their classrooms for several reasons. Factors included the lack of resources and materials, budgetary constraints, and support from school leaders. Lumpe noted differences between elementary and secondary teachers toward STS implementation. Teachers in elementary schools often avoided the STS approach due to anxiety in addressing controversial topics with students. Critics of the STS approach feel that using an instructional strategy such as this will not allow the depth of content to be covered will not be substantial enough for students to be successful (Yager, 2006).

Totten and Pedersen (2001), similar to Lumpe (1998), attempted to understand teachers' beliefs and opinions about STS instruction in their classrooms. Elementary teacher beliefs about curriculums and textbooks, personal beliefs about STS issues, and teacher-student interactions were examined. Teachers received the "Attitudes and Beliefs Survey," consisting of seven sections examining instructional tools such as curriculum and textbooks. When examining the curriculum goals of these 
teachers, over $70 \%$ felt that social issues had a strong place in the curriculum. Over $68 \%$ stated that their curriculum was largely derived from the textbook. Most participants stated that they attempted to integrate issues relevant to their students into the curriculum. Thus, it truly appears that while many teachers have knowledge about STS issues, there still appears to be a disconnect between theory and implementation. Many apparent reasons cited included, lack of time, planning difficulties, and concerns about discussing controversial topics in the classroom. The development of prospective and practicing elementary teacher's dispositions toward science is poor, and many teachers lack the confidence to teach science effectively (Watters, 2000). Science teaching at the elementary level continues to be a source of concern that little current research evidence appears to be available on. It was a challenge to further locate recent studies examining either the effects of preservice or in-service science teachers' perspectives toward STS issues. Typically, social issues do not seem to become an apparent focus in the curriculum until middle or high school (Harms \& Yager, 1981).

A recent study of Kumar (2008) proposed a survey of science and social studies curriculum supervisors in public schools to understand the types of teacher professional development activities involving STS education in the State of Florida. A survey questionnaire was developed by university science and social studies educators examining four categories of concern: overall implementation, implementation by discipline and grade, reactions to STS education, and instructional materials being utilized. Approximately, $65 \%$ of all respondents stated that they had been exposed to STS education, while only $29 \%$ of the districts stated that they implemented it. Only $4 \%$ of these districts implementing STS provided funding for teacher development. When examining the districts reporting the use of STS, $16 \%$ report using it at the elementary level, $47 \%$ at the middle school level, and $35 \%$ at the secondary level. Startling was the fact that only $12 \%$ of the responding participants viewed STS as positive. STS education will not be successful without the commitment of all teachers. While much positive data and studies have been conducted over the last ten years, the goals of STS implementation envisioned by NSTA are still far from complete.

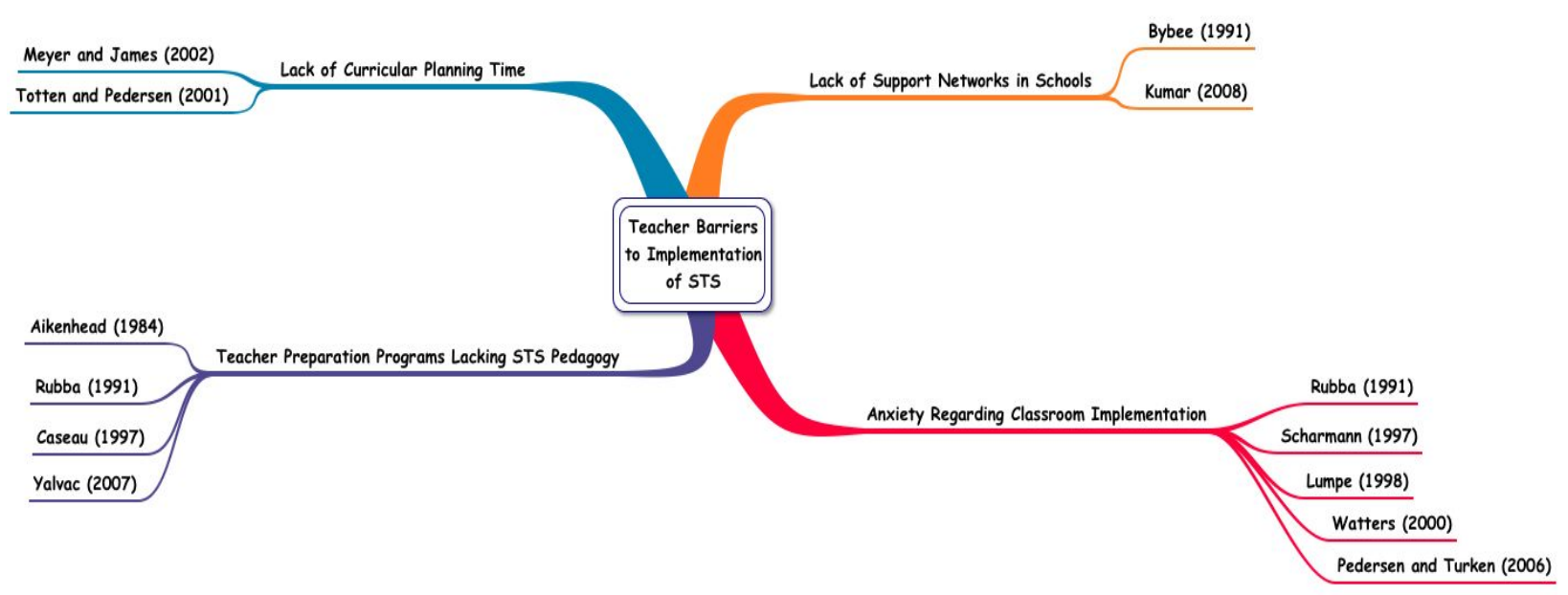

Figure 3: Perceived barriers associated with successful implementation of STS instruction by pre-service and inservice teachers.

Positive Implementation of STS: Light at the End of the Tunnel.

STS education provides students with opportunities to examine a topic from multiple perspectives (Kumar, 2000). The following section presents some of the research that has demonstrated the positive and beneficial outcomes of STS-based instruction.

Several studies have reported positive interactions with STS in their classrooms over the last several years. Tsai (2001) depicted the views and opinions of a science teacher on STS instruction after implementing a two-semester STS-based high school course. These "scientific epistemological views" 
(SEVs) (p.24) tie a teacher's perspectives to their instructional pedagogy. Data were also collected from a series of five formal interviews conducted prior to and until the conclusion of the study. At the conclusion of the study, the participant seemed to indicate that STS instruction also embodied teaching students in a constructivist environment. Based on observations of her student's activities, the student teacher began to understand that learning occurs when students were able to construct their own knowledge. Thus, STS implementation thoroughly helped the teacher to understand the strategies and characteristics of STS instruction.

A study examining the use of STS to teach science to special education students was conducted by Caseau (1997). Students with learning disabilities experience problems with critical thinking, problem solving, concept development, and an overall lack of motivation. The benefit with utilizing an STS approach is that it begins with the student's interests. Student motivation increases when the learning environment becomes active and relevant to their personal experiences. Most of the teachers, in the study, indicated that they typically utilized direct instruction in their classrooms as the main instructional strategy. Surprisingly, at the conclusion of the study, several academic and social gains were noted of the participants' students. For instance, one teacher noted in terms of motivation, that, "STS makes learning relevant to issues in student's lives and students are motivated because they are personally involved." Secondly, in terms of motivation for teachers, one teacher noted that, "The STS approach allowed me to take a step back and observe students discover things rather than give all the answers" (Caseau, 1997).

\section{Summary}

The research reviewed in this section presented a wide range of attitudes of in-service teachers toward implementation of STS curriculum. Wide disparities can be identified between elementary and secondary education professionals. Development of elementary education teacher dispositions toward science is poor, and this is likely impacting their confidence to teach science content effectively. These studies draw attention to several barriers to implementation including lack of time, planning difficulties and district administrative and budgetary constraints. Toward the opposite end of the spectrum, when focusing on educators successfully implementing STS, participants found that STS instruction is beneficial to meeting the needs of all students in the mainstream classroom (Caseau, 1997) in a manner that is aligned to constructivist learning theories (Tsai, 2001).

\section{Pre-Service Teacher Views: What are the influences of teacher preparation programs?}

One of the greatest constraints to universal implementation of STS involves the lack of compatibility of pre-service teacher goals and beliefs toward STS (Amirshokoohi, 2010). This particular section of the literature review will focus on examining several integral studies demonstrating the influence that STS-based preparation has had on pre-service teachers. Figures 4 and 5 summarize U.S. and international studies focusing on pre-service teachers and STS education.

An early study conducted by Aikenhead (1984) demonstrated that much of the discrepancy between the goals of NSTA and the actual implementation of STS are due largely to pre-service teacher education training programs. Most of the teachers are led to believe during their pre-service training programs that they are merging into a specific scientific discipline, of which they will eventually do the same for their own students.

Scharmann (1997) indicated a shortcoming in the available information regarding pre-service science teacher's perceptions on the orientations toward STS. The study examined secondary education students enrolled in a science methods course at a midwestern university. This was an action based research project integrating a high degree of self-evaluation and self-reflection to help determine why students would be hesitant to implement a societal-based or issue-based perspective in the classroom. Data was collected using two instruments, the Contemporary Goals Survey (CGS) and a set of openended response questions. The most startling fact that supports the lack of STS in public schools in our country is summarized in one alarming statistic. Between $60 \%$ and $75 \%$ of participants in the study did not feel confident enough to be able to implement STS themes in their classrooms. An 
additional $25 \%$ reported that their cooperating teacher during the student teaching experience did not support the implementation of STS in the classroom, because "it did not look like real science." This raises a great implication for teachers entering the field, as it fails to build the confidence in using these effective methodologies in the classroom.

Meyer and James (2002) aimed to determine whether teacher-training programs could provide preservice science teachers with the information and knowledge necessary to acquire an interest in STS. It was also critical to see if this enthusiasm toward STS would carry over into the pre-service teachers' own classrooms. This qualitative study was conducted with pre-service science teachers enrolled in a science methods course. The summative exercise for the project involved an STS fair that enabled the students to display their projects to fellow faculty and students. Most students reported that they felt comfortable working collaboratively in groups in conjunction with the development of strong communication skills and integrating subject matter across disciplines. Students felt that working with content in an integrated format helped them to understand the importance of allowing their own students to understand the importance of real life application in the learning process. Three years after the completion of the study, seven open-ended questions were sent to the former science method student participants, now practicing teachers, to determine how they had subsequently integrated STS methodologies into their own practice. All respondents emphasized the importance of making STS units that were multidisciplinary in nature. However, only one in-service teacher reported having created STS units for use in her own classroom. The respondents who had not implemented STS in their classrooms cited curricular planning and time constraints as reasons for not carrying out this behavior.

Dass (2005) examined the impression that STS approaches had on the views and views of pre-service science teachers with regards to science education reform. The study focused on two science methods courses from a mainly commuter public university. Qualitative data was collected and consisted of reflective journals, class presentations of STS investigations, and in-depth interviews conducted at the conclusion of the semester. Data analysis concluded that overall most students viewed the STS process in a positive fashion and felt that they could use it with their own students. At the start of the study, both groups of students did not completely agree with the STS experience. As the study progressed, students became more comfortable with and started to see the value of STS instruction. Among the fifteen students that went into student teaching after methods, there were two cases of teachers implementing STS in practice. It was concluded that STS pedagogy helps pre-service science teachers to understand issues they may not normally be aware of and thus better understand the nature of scientific inquiry as they investigate possible solutions to these questions. Finally, it helps students to see the value and excitement of entering into a learning process where students have the ability to search for answers to their own questions (Dass, 2005). 


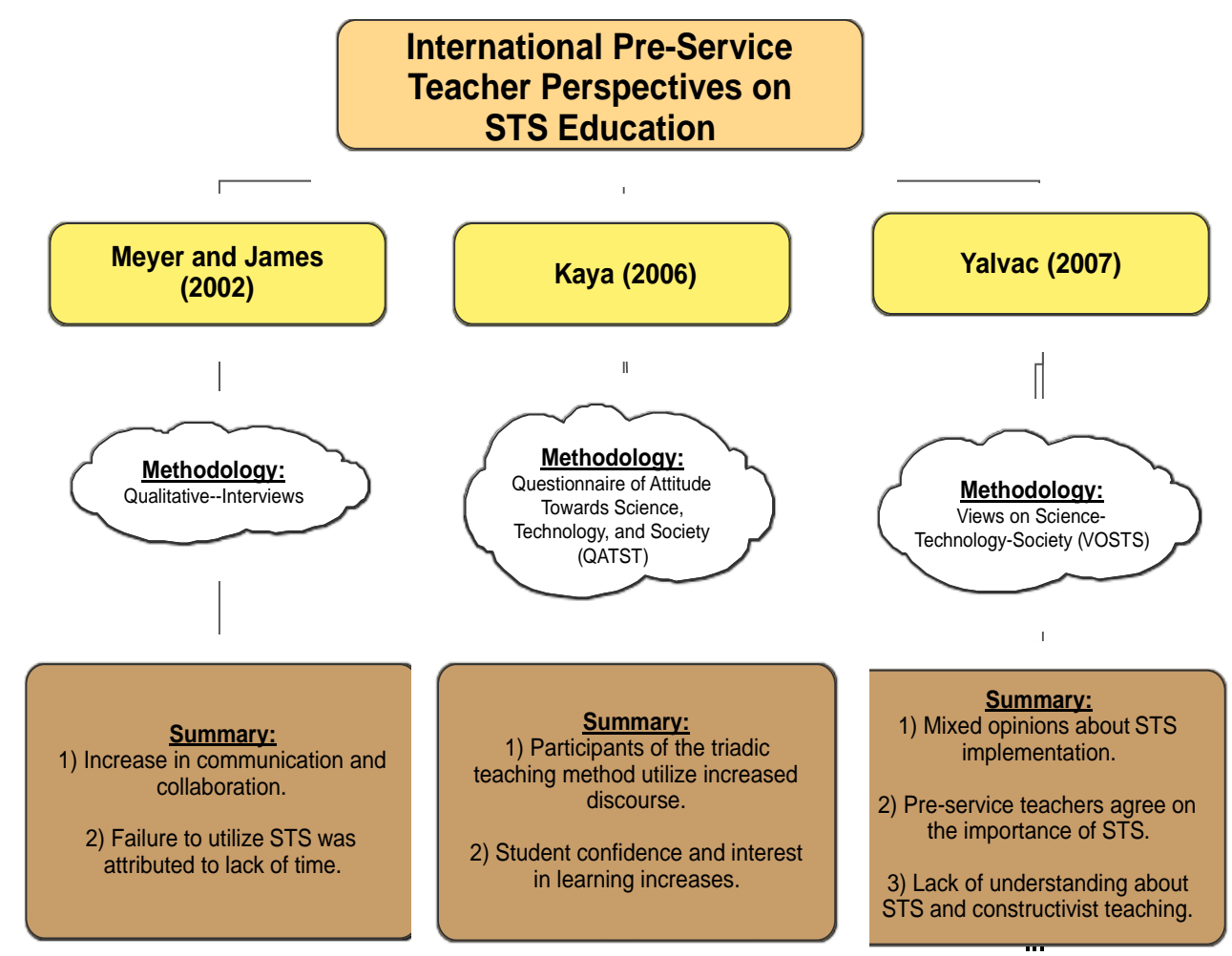

Figure 4: Selected studies and their conclusions of teacher perceptions on STS globally.

Pedersen and Turken (2006) conducted a study to identify and examine conceptions of pre-service elementary education teachers to teaching social issues in the K-12 classroom. Participants in the study were elementary education majors at a Southwestern University. Thirty-three students participated in an online-survey documenting their preconceptions before participating in the study. Respondents seemed to indicate that reading textbooks, magazines/journals, and books were the primary methods for students to acquire information on societal issues in the classroom. Many of the pre-service teachers indicated that while they felt they could have an influence on social issues at the local city level, many expressed the disbelief that they could foster change at the state, national, and global levels. These pre-service teachers also indicated that they felt that students were not obtaining information on social issues from activities such as field trips or projects, but from television and other news media outlets. This leaves the question, how do we know that our students are getting unbiased information on these social issues if they are not properly dissected in our classrooms?

Kaya (2006) focused research on the development of middle school science teachers in Turkey. The researchers developed an instrument termed the "Questionnaire of Attitude towards Science, Technology and Society" (QASTS) to examine trends in the attitudes of teachers toward STS. Emphasis was placed on the utilization of a triadic teaching approach to STS consisting of library research to drive the design of scientific investigations, mini-scientific symposia, and lastly poster presentations to members of the school community. Students participating in the study indicated that they were able to select scientific and technological issues to study freely, while the strategies utilized increased confidence in their own work.

An additional study examined the perspectives of both pre-service and in-service teachers with respect to science and technology. Yalvac (2007) concluded that both pre and in-service teachers in Turkey had mixed opinions regarding whether science learning should be content or process centered. A survey instrument called the "Views on Science-Technology-Society (VOSTS) instrument was utilized to collect information on a broad range of STS topics. The study revealed that there was no strong consensus on how Turkish pre-service teachers defined science and viewed the application of science as technology. The implications of this study deals with the practices of pre-service science teachers, and the practices of science educators. 
Amirshokoohi (2010) examined elementary pre-service teachers' level of environmental literacy and views toward STS before enrolling in any science methods course. Participants of the study indicated a willingness to teach socially contextualized issues, but low scores on instruments measuring environmental literacy indicate the necessity for preparation programs to allow teacher candidates to garner opportunities to create connections between their beliefs and knowledge of STS.

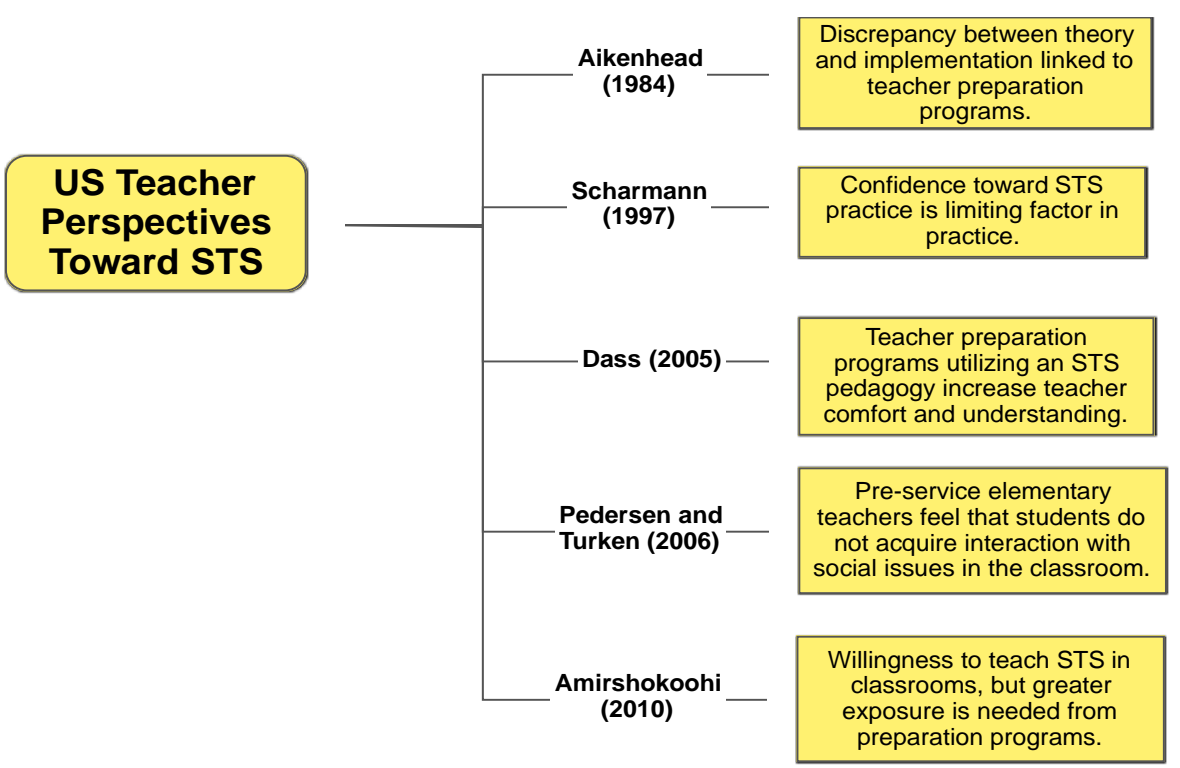

Figure 5: U.S. Pre-service teacher perspectives on the ability to implement STS education.

\section{Summary}

Students need to learn content in a manner that is more meaningful to them. Even in the primary grades, students should learn that science is more than performing a series of organized steps to reach a desired outcome, but learning ways to help citizens to lead a better life through scientific literacy and democracy. Without support from administrators, university preparation programs, and interdisciplinary teams of teachers, the STS education reform movement could become in jeopardy (Mansour, 2009). Teacher education preparation is especially imperative in allowing pre-service teachers to acquire the knowledge and skills necessary for implementing effective STS-based instruction.

\section{Summary and Implications}

The movement toward standards that reflect the growing demand for scientifically literate citizens is paramount. Students leave high school finding the need to make increasingly influential decisions about scientifically relevant issues. Curriculum must reflect student experiences and provide situations that promote opportunities for meaningful connections to be made between content materials and societal issues. The NGSS provide a framework that relates science, technology, society and the environment. NGSS focuses on the interdependence of these issues to help students define and investigate problems that affect their local and national communities (NGSS, 2013).

Several important conclusions can be drawn from the selected studies summarized throughout this review. Students who participated in a learning environment enriched with STS techniques demonstrated increased interest in the study of science and pursuit of STEM careers. In the classroom, teachers noted increased process and creativity skills when students are engaged in instruction that promotes meaningful discourse with peers. Classroom learning environments moved from passive, didactic atmospheres to those that featured active, constructivist-based learning techniques. 
In-service teachers indicated several barriers to successful implementation. Several studies make note of the fact that pre-service teachers are not receiving adequate exposure to STS strategies in their preparation programs making them less likely to implement these practices in their own classrooms. In other circumstances, STS is not explained clearly, leaving teachers to believe that STS is a separate, un-related discipline of science teaching. $25 \%$ of pre-service teachers in one study indicated that their cooperating teachers did not support STS since "it did not look like real science" (Scharmann, 2007). In-service teachers report difficulty switching roles from the facilitator to the guide of the learning process. Many other respondents noted failed support from district resources such as the budget or administration. Other barriers mentioned included lack of curricular planning time and lack of exposure to STS methodology during teacher preparation experiences. On a positive note, the literature review did highlight some of the successes of STS instruction in the classroom for teachers. Not only were teachers better able to help students understand complex issues; they were also able to positively contribute to the success of exceptional learners in the mainstream classroom.

While much progress can be seen from the recent studies pertaining to STS, several areas were found to be lacking by the researchers when conducting the review of the pertinent literature. First and foremost, there is a significant lack of relevant knowledge towards how STS instruction is being utilized in the elementary school classrooms. Few studies have explored teacher and student perspectives and opinions before and after STS instruction. This may in fact be due to evidence indicated in some of the above mentioned studies, stating that elementary teachers shy away from STS pedagogy for fear of bringing controversial issues into the classroom and a lack of expertise toward science. Overall, there seems to be a lack of information pertaining to the utilization of STSbased studies in the United States for both pre-service and in-service teachers. Few studies could be located discussing the use of STS by practicing teachers. Several reasons that this lack of research data is likely could be due to low percentages of teachers utilizing STS due to intense instructional planning and time constraints. Further studies are necessary to fully examine the low number of teachers who are willing to implement STS-based instruction in their classrooms.

Other areas that should also be explored are the types of STS curriculum and pedagogy that are being implemented in the classrooms and teacher education programs. There may be variations as to how STS is defined and implemented. Another area to explore is to examine teaching practices of novice teachers who go through STS-based training in their teacher education programs to see the extent of implementing what they have gained.

Overall, this review has indicated that STS is still growing and its importance has been realized by several teacher education programs around the nation and internationally. Student benefits, including, increased participation in society, increased motivation to learn science, and development of higher order skills such as creativity and processing become fully developed in these environments.

\section{References}

Abd-El-Khalick, F. (2003). Socioscientific issues in pre-college classrooms. In The role of moral reasoning on socioscientific issues and discourse in science education, ed. D. L. Zeidler, 41-62. Dordrecht, The Netherlands: Kluwer Academic Publishers.

Achieve, Inc. (2013). Next Generation Science Standards: Science, Technology, Society, and the Environment. Achieve, Inc., Appendix J.

Aikenhead, G. (1984). Teacher decision making: The case of Prairie High. Journal of Research in Science Teaching, 21(2), 167-186.

Aikenhead, G. (1992). The Integration of STS in Science Education. Theory Into Practice, 31(1), 27-35.

Amirshokoohi, A. (2010). Elementary Pre-service Teachers' Environmental Literacy and Views Toward Science, Technology, and Society (STS) Issues. Science Educator, 19(1), 56-62.

Amirshokoohi, A., \& Kazempour, M. (2010). The Biodiversity Community Action Project: An STS Investigation. The American Biology Teacher, 72(5), 288-293.

Banilower, E. R., Smith, P. S., Weiss, I. R., Malzahn, K. A., Campbell, K. M., \& Weis, A. M. (2013). Report of the 2012 National Survey of Science and Mathematics Education. Chapel Hill, NC: Horizon Research, Inc.

Bybee, R.W. (1991). Science-Technology-Society in Science Curriculum: The Policy-Practice Gap. Theory Into Practice, 30(4), 294-302.

Caseau, D., \& Norman, K. (1997). Special Education Teachers Use Science-Technology-Society (STS) Themes to Teach Science to Students With Learning Disabilities. Journal of Science Teacher Education: 8(1), 55-68.

Dass, P.M. (2005). Using a Science/Technology/Society Approach To Prepare Reform-Oriented Science Teachers: The Case of a 
Secondary Science Methods Course. Issues in Teacher Education: 14(1), 95-108.

Kim, M. \& Roth, W.M. (2008). Rethinking the Ethics of Scientific Knowledge: A Case Study of Teaching the Environment in Science Classrooms. Asia Pacific Education Review: 9(4), 516-528.

Kumar, D. \& Fritzer, P. (1998). A Study of Science-Technology-Society Education Implementation in the State of Florida. Journal of Social Studies Research: 22(1), 14-18.

Kumar, D.D., \& Chubin, D.E. (2000). STS: Adding Value to Research and Practice. Journal of Science Education and Technology: 9(2), 135-139.

Lee, M-K., \& Erdogan, I. (2007). The Effect of Science-Technology-Society Teaching on Students' Attitudes toward Science and Certain Aspects of Creativity. International Journal of Science Education: 29(11), 1315-1327.

Lumpe, A.T., Haney, J.J., \& Czerniak, C.M. (1998). Science Teacher Beliefs and Intentions to Implement Science-TechnologySociety (STS) in the Classroom. Journal of Science Teacher Education: 9(1), 1-24.

Mansour, N. (2009) Science-Technology-Society (STS): A New Paradigm in Science Education. Bulletin of Science Technology Society, 29, 287-297.

Meyer, J.D., and R.K. James. (2002, April). STS For Pre-Service Teachers: Does It Translate In The Classroom? Paper presented at the Annual Meeting of the National Association for Research in Science Teaching, Philadelphia, PA.

Nafiz Kaya, O., Yager, R., \& Dogan, A. (2009). Changes in Attitudes Towards Science-Technology-Society of Pre-Service Science Teachers. Research in Science Education, 39, 257-279.

National Research Council. (1996). National science education standards. Washington, DC: National Academy Press.

National Science Teachers Association. (1982). Science-technology-society: Science education for the 1980's. Position Paper. Washington DC: National Science Teachers Association.

National Science Teachers Association. (2010). Teaching Science and Technology in the Context of Societal and Personal Issues. Position Statement. Washington DC: National Science Teachers Association.

Pedersen, J.E., \& Totten, S. (2001). Beliefs of Science Teachers Toward the Teaching of Science/Technological/Social Issues: Are We Addressing National Standards? Bulletin of Science Technology Society 2001, 21, 376.

Pedersen, J.E. \& Turkmen, H. (2005). Pre-service Teachers' Knowledge and Perceptions of Social Issues. STS Today, 17(2), Retrieved November 20, 2012 from, http:/ / ege.academia.edu/HakanTurkmen/Papers/577368/Pre service_Teachers_Knowledge_and_Perceptions_of_Social_Issues

Pedretti, E. (1999). Decision Making and STS Education: Exploring Scientific Knowledge and Social Responsibility in Schools and Science Centers Through an Issues-Based Approach. School Science and Mathematics, 99(4), 174-181.

Rubba, P.A. (1991). Integrating STS into School Science and Teacher Education: Beyond Awareness. Theory Into Practice, 30(4), 303-308.

Rubba, P.A., \& Harkness, W.L. (1993). Examination of Pre-Service and In-Service Secondary Science Teachers' Beliefs about Science-Technology-Society Interactions. Science Education, 77(4), 407-431.

Scharmann, L.C. (1997). Preservice Secondary Science Teachers' Orientation Towards Science-Technology-Society (STS) Education. Electronic Journal of Science Education, 1(3).

Sweeny, A.E. (2001). Incorporating Multicultural and Science-Technology-Society Issues Into Science Teacher Education Courses: Successes, Challenges, and Possibilities. Journal of Science Teacher Education, 12(1), 1-28.

Tsai, C.C. (2002). A Science Teacher's Reflections and Knowledge Growth About STS Instruction After Actual Implementation. Science Education, 86(1), 23-41.

Watters J. J. \& Ginns, I. S. (2000). Developing motivation to teach elementary science: Effect of collaborative and authentic learning practices in pre-service education. Journal of Science Teacher Education, 11(4), 277-313.

Yager, R.E., Tamir, P., \& Huang, D. (1992). An STS Approach to Human Biology Instruction Affects Achievement \& Attitudes of Elementary Science Majors. The American Biology Teacher, 54(6), 349-355.

Yager, R.E. (1993). Science-Technology-Society as reform. School Science and Mathematics, 93(3), 145-151.

Yager, R.E. Tamir, P., Kellerman, L. (1994). Success with STS in Life Science Classrooms, Grades 4-12. The American Biology Teacher, 56(5), 268-272.

Yager, R.E., and M.V. Lutz. (1995). STS to Enhance Total Curriculum. School Science and Mathematics, 95(1), 28-35.

Yager, S.O., Yager, R.E. \& Lim, G. (2006). The Advantages of an STS Approach Over a Typical Textbook Dominated Approach in Middle School Science. School Science and Mathematics, 106(5), 248-260.

Yager, R.E., Choi, A., Yager, S.O. \& Akcay, H. (2009). Comparing Science Learning Among $4^{\text {th }}$, $5^{\text {th }}$-, and $6^{\text {th }}$-Grade Students: STS Versus Textbook-Based Instruction. Journal of Elementary Science Education, 21(2), 15-24.

Yalvac, B., Tekkaya, C., Cakiroglu, J., \& Kahyaoglu, E. (2007). Turkish Pre-Service Science Teachers' Views on ScienceTechnology-Society Issues. International Journal of Science Education, 29(3), 331-348.

Yoruk, N., Morgil, I, \& Secken, N. (2009). The effects of science, technology, society and environment (STSE) education on students' career planning. US-China Education Review, 6(8), 68-74. 